\title{
Effects of Physician-Based Preventive Oral Health Services on Dental Caries
}

\author{
Ashley M. Kranz, PhDa, John S. Preisser, PhD ${ }^{b}$ R. Gary Rozier, DDS, MPH
}

BACKGROUND: Most Medicaid programs reimburse nondental providers for preventive dental services. We estimate the impact of comprehensive preventive oral health services (POHS) on dental caries among kindergarten students, hypothesizing improved oral health among students with medical visits with POHS.

METHODS: We conducted a retrospective study in 29173 kindergarten students by linking Medicaid claims (1999-2006) with public health surveillance data (2005-2006). Zero-inflated regression models estimated the association between number of visits with POHS and (1) decayed, missing, and filled primary teeth (dmft) and (2) untreated decayed teeth while adjusting for confounding. RESULTS: Kindergarten students with $\geq 4$ POHS visits averaged an adjusted $1.82 \mathrm{dmft}$ (95\% confidence interval: 1.55 to 2.09), which was significantly less than students with 0 visits $(2.21$ dmft; $95 \%$ confidence interval: 2.16 to 2.25 ). The mean number of untreated decayed teeth was not reduced for students with $\geq 4$ POHS visits compared with those with 0 visits.

concLusIoNs: POHS provided by nondental providers in medical settings were associated with a reduction in caries experience in young children but were not associated with improvement in subsequent use of treatment services in dental settings. Efforts to promote oral health in medical settings should continue. Strategies to promote physician-dentist collaborations are needed to improve continuity of care for children receiving dental services in medical settings.

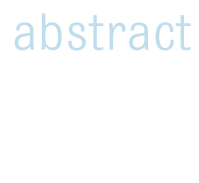

${ }^{a}$ Department of Pediatric Dentistry, School of Dentistry, and Departments of ${ }^{b}$ Biostatistics and ${ }^{c}$ Health Policy and Management, Gillings School of Global Public Health, University of North Carolina at Chapel Hill, Chapel Hill, North Carolina

Dr Kranz contributed to the conception and design of the study, analysis and interpretation of data, and drafting and revising of the manuscript; Dr Preisser contributed to the design of the study and the analysis and interpretation of data and reviewed and revised the manuscript; Dr Rozier acquired data, contributed to the conception and design of the study and analysis and interpretation of data, and reviewed and revised the manuscript; and all authors approved the final manuscript as submitted.

www.pediatrics.org/cgi/doi/10.1542/peds.2014-2775

DOI: $10.1542 /$ peds.2014-2775

Accepted for publication Apr 14, 2015

Address correspondence to Ashley M. Kranz, PhD, Department of Pediatric Dentistry, UNC School of Dentistry, Koury Oral Health Sciences Building, Room 4505, Campus Box 7455, Chapel Hill, NC 275997455. E-mail: akranz@unc.edu

PEDIATRICS (ISSN Numbers: Print, 0031-4005; Online, 1098-4275).

Copyright (C) 2015 by the American Academy of Pediatrics

FINANCIAL DISCLOSURE: The authors have indicated they have no financial relationships relevant to this article to disclose.

FUNDING: Supported by grants R01 DE013949 and R03 DE017350 from the National Institute of Dental and Craniofacial Research (NIDCR). The content is solely the responsibility of the authors and does not necessarily represent the official views of the NIDCR or the National Institutes of Health. Dr Kranz was supported by a National Institutes of Health T90 training grant (grant NIH/NIDCR 5T90DE021986-03). Funded by the National Institutes of Health (NIH).

POTENTIAL CONFLICT OF INTEREST: The authors have indicated they have no potential conflicts of interest to disclose.
WHAT'S KNOWN ON THIS SUBJECT: The US Preventive Services Task Force recommends primary care clinicians apply fluoride varnish to the teeth of all young children, but no studies have examined the effect of comprehensive preventive oral health services on children's clinical oral health status.

WHAT THIS STUDY ADDS: Comprehensive preventive oral health services delivered by primary care clinicians can help improve the oral health of Medicaid-enrolled children, but more work is needed to link medical and dental offices to ensure the continuity of dental care for these children 
Despite improvements in US children's oral health, ${ }^{1,2}$ reports from the past decade have revealed large disparities in oral health; poor access to care for some subgroups, leading to large amounts of untreated decay; and a high and increasing prevalence of caries among preschool-aged children. ${ }^{2}$ National surveys report that approximately one-third of children aged 2 to 5 years experienced dental caries in 1999-20023; 1 in 4 children aged 3 to 5 years living in poverty in 2009-2010 had untreated caries, 2.5 times that of other children ${ }^{4}$; and only $4.1 \%$ of children younger than 4 years had professional fluoride treatments in 2009. ${ }^{3}$

Because most children have more physician visits than dentist visits during the first 3 years of life, expanding the traditional involvement of primary care medical practitioners in oral health promotion has been proposed to address these dental problems. ${ }^{5-8,9,10}$ Access to preventive oral health services (POHS) would be increased if provided by physicians and nurses because they can deliver preventive services in communities without a sufficient dental workforce and for patients unlikely to visit a dentist, monitor children's oral health, prioritize referrals, and help facilitate dental visits for the highest-risk children until they establish a dental home.

The US Preventive Services Task Force (USPSTF) recommends primary care clinicians apply fluoride varnish to the teeth of all children aged $\leq 5$ years and state Medicaid programs incorporating this approach have become widespread since 1998.11,12 Several states reimburse physicians through their public insurance programs for dental screenings and oral health counseling, and almost all reimburse physicians for the application of fluoride varnish. ${ }^{12,13}$ The literature suggests that physicians will adopt these services and provide quality care that is effective in increasing access to preventive services, reducing treatment needs, averting hospitalizations, and lowering Medicaid costs. ${ }^{14-20}$ Studies reporting improved oral health have either provided circumstantial evidence on the basis of administrative claims ${ }^{18,19}$ or have not examined comprehensive services, which include fluoride varnish applications. ${ }^{15}$ This study extends previous work by evaluating the impact of comprehensive POHS, which includes screening and risk assessment, fluoride varnish applications, and parental oral health counseling, provided in medical offices by nondental providers, on the dental caries experience of children enrolled in North Carolina's (NC's) Medicaid program.

\section{METHODS}

\section{Study Design}

We conducted a retrospective cohort study using surveillance data and NC Medicaid files for children enrolled in kindergarten during 2005-2006. Children would have received POHS from 2000-2003, when NC Medicaid reimbursed providers for up to 6 visits per child up to 3 years of age. ${ }^{21}$ Because this time period coincides with the beginning of implementation, many children did not visit participating providers or receive the recommended number of visits. We use this population to examine the association between the number of medical visits with POHS and subsequent oral health outcomes. Children with or without POHS could also have received dental visits, the recommended standard of care in areas with a sufficient dental workforce.

\section{Sample}

Oral health surveillance data were available from the NC Oral Health Section for 92127 kindergarten children in 98 of $100 \mathrm{NC}$ counties (82\% of the state's public school kindergarten enrollment). ${ }^{22}$ These data are collected annually by public health dental hygienists who conduct standardized screenings of all kindergarten students in public schools. Screenings provide information about overall dental caries experience and the amount of dental treatment received, and these surveillance data have shown good reliability when compared with an experienced dentist performing a standard examination. ${ }^{22-24} \mathrm{~A}$ strength of this study is the independent assessment of caries experience because it is not biased by knowledge of enrollment in Medicaid or receipt of POHS. Medicaid enrollment and claims files for 2000-2006 were obtained from the NC Division of Medical Assistance. These files provide information about each enrolled child, including the following: demographic characteristics, length of enrollment, and services reimbursed by Medicaid.

The surveillance data and Medicaid files were previously linked by using Link King software (Camelot Consulting, Olympia, WA), which uses probabilistic and deterministic methods to match individual records on the basis of name, date of birth, gender, race, and county of residence. ${ }^{25,26}$ From the kindergarten surveillance data, 34 743 children were successfully matched to Medicaid claims of children enrolled before age 1 year and were still enrolled after their first birthday. Children were excluded from the analysis if they had a nonunique identification number $(n=442)$, had $<1$ year of Medicaid enrollment before 3 years of age ( $n=3095)$, had POHS claims posteligibility $(n=82)$, or were missing oral health surveillance measures ( $n=1951$ ). Our sample included 29173 children with Medicaid claims, which is comparable to the proportion of children of this age enrolled in NC Medicaid. 27 


\section{Measures}

We analyzed caries experience, a measure of a child's dental health status, using a composite index of the number of decayed, missing, and filled teeth (dmft), derived from a visual inspection of the primary dentition of kindergarten students. Primary incisors were excluded from the count of missing teeth because they could be missing for noncarious reasons, mostly natural exfoliation. We also analyzed the number of untreated decayed teeth (dt), a measure of the extent to which a child's treatment needs for dental caries are being met. Both measures have a potential range of 0 to 20 primary teeth.

The main explanatory variable indicates the number of medical visits with POHS (0 [reference group], 1, 2, 3 , and 4-6) received before a child's third birthday. Visits with POHS were identified with reimbursement for any combination of Current Dental Terminology codes for screening, counseling, and topical fluoride. Physicians were required to bundle these services to qualify for reimbursement.

The selection of explanatory variables was guided by the behavioral model for health care service use. ${ }^{28} \mathrm{We}$ hypothesized that the receipt of POHS would be influenced by child-level predisposing characteristics (gender, race [white, black, other], Hispanic ethnicity, and special health care needs), enabling characteristics (total months enrolled in Medicaid and well-child visits), and need (previous receipt of caries-related treatment, an indicator of high caries risk). ${ }^{29}$ In addition, characteristics of the health care system and external environment (POHS received in a health department and county-level measures of rural or urban status ${ }^{30}$; proportion of population with fluoridated public drinking water; number of dentists, pediatricians, and physicians $^{31}$; and Medicaid-eligible individuals $<18$ years per 10000 population ${ }^{32}$ ) were hypothesized to affect POHS.

\section{Propensity Score Estimation}

Because children were not randomly assigned to receive POHS, our effect estimates could potentially be biased If providers target $\mathrm{POHS}$ at children with or at high risk of caries, the effect of POHS on dental caries may be underestimated. Conversely, if lower-risk children were more likely to receive POHS, its impact on caries may be overestimated. To address observed confounding, we estimated propensity scores with inverse probability of treatment weights (IPTWs). ${ }^{33,34}$ The goal of IPTWs was to obtain a group of children who were as similar as possible, differing only in their exposure to POHS. ${ }^{33}$

Propensity scores were estimated by using logistic regression to predict the likelihood of receiving POHS during a medical visit as compared with not receiving POHS, controlling for the aforementioned covariates, including squared terms of continuous variables and excluding the variable indicating receipt of treatment due to its relationship with the exposure variable. For each child, we calculated standardized weights, an approach that assigns greater weight to children who received POHS, but who have characteristics more similar to children who did not have any POHS and vice versa. ${ }^{34}$ Groups were more similar after IPTW adjustment, as evidenced by the similar distribution of propensity scores among children with and without POHS (Supplemental Fig 3) and improved covariate balance shown by absolute standardized differences $<10 \%$ (Supplemental Fig 4). 35

\section{Analytical Approach}

One-way rank analysis of variance (Kruskal-Wallis test) was used to test for differences in mean dmft and $\mathrm{dt}$ between children with $0,1,2,3$, and $\geq 4$ visits with POHS. We modeled dmft and dt using zero-inflated negative binomial (ZINB) regression models. For the logit part of the ZINB models, odds ratios indicate the odds of having excess zero dmft or dt, a nonrandom zero in the sense of being considered not at risk of caries. For the negative binomial parts, our response variable is the number of $\mathrm{dmft}$ or $\mathrm{dt}$ among children considered to be at risk of caries, interpreted as an incident rate ratio. We estimated marginal mean outcomes and 95\% confidence intervals (CIs) using 500 bootstrap replications, by averaging the predicted marginal means across all children (ie, combining ZINB regression coefficients from model parts for not-at-risk and at-risk classes of children) fixing the number of visits with POHS at $0,1,2,3$, and $\geq 4$, in turn, while allowing other covariates to be adjusted at their observed values. ${ }^{36}$ In addition, to assess overall effects of POHS, we averaged differences in the predicted outcomes over all children assuming they had 0 visits and their outcome assuming they had $1,2,3$, and $\geq 4$ visits with POHS, respectively, and assessed these using Wald tests and 95\% CIs. ${ }^{37}$ All tests were performed in Stata/IC 12 (StataCorp, College Station, TX) with the use of a 0.05 significance level. This study was approved by an institutional review board at the University of North Carolina at Chapel Hill.

\section{RESULTS}

\section{Unadjusted Analysis}

Table 1 indicates that $69.7 \%$ of children had 0 visits with POHS ( $n=$ 20 322). Among children who received POHS ( $n=8851), 51.3 \%$ had 1 visit ( $n=4540), 29.3 \%$ had 2 visits $(n=2596), 13.1 \%$ had 3 visits ( $n=$ 1160 ), and $6.3 \%$ had $\geq 4$ visits ( $n=$ 555). Children with more POHS visits had more well-child visits, on average, before their third birthday and lived in counties with more Medicaid-eligible children and fewer dentists. 
TABLE 1 Characteristics of the Unweighted Sample of NC Medicaid Enrollees

\begin{tabular}{|c|c|c|c|c|c|c|}
\hline & $\begin{array}{c}\text { Overall } \\
(N=29173)\end{array}$ & $\begin{array}{c}0 \text { Visits } \\
(n=20322)\end{array}$ & $\begin{array}{c}1 \text { Visit } \\
(n=4540)\end{array}$ & $\begin{array}{c}2 \text { Visits } \\
(n=2596)\end{array}$ & $\begin{array}{c}3 \text { Visits } \\
(n=1160)\end{array}$ & $\begin{array}{l}\geq 4 \text { Visits } \\
(n=555)\end{array}$ \\
\hline \multicolumn{7}{|l|}{ Child-level variables } \\
\hline Count of $\mathrm{dmft}^{\star \star}$ & $2.19(3.19)$ & $2.23(3.22)$ & $2.16(3.16)$ & $2.14(3.18)$ & $2.02(3.07)$ & $1.76(2.98)$ \\
\hline Percentage of children with any $\mathrm{dmft}$ & 47.9 & 48.3 & 47.7 & 46.7 & 46.2 & 43.2 \\
\hline Count of $d t$ & $0.76(1.78)$ & $0.78(1.82)$ & $0.73(1.70)$ & $0.69(1.60)$ & $0.72(1.77)$ & $0.51(1.34)$ \\
\hline Percentage of children with any $d t$ & 25.3 & 25.6 & 25.2 & 24.9 & 24.5 & 21.8 \\
\hline Months enrolled on Medicaid before age $3^{\star \star \star}$ & $31.7(3.9)$ & $31.6(4.2)$ & $32.0(3.4)$ & $32.1(3.1)$ & $32.3(2.7)$ & $32.6(1.8)$ \\
\hline \multicolumn{7}{|l|}{ Race (reference group: other)* } \\
\hline White & 41.3 & 41.7 & 41.6 & 38.5 & 40.4 & 38.4 \\
\hline Black & 41.5 & 41.6 & 40.8 & 41.5 & 41.8 & 42.7 \\
\hline Hispanic ethnicity*夫 & 8.6 & 8.8 & 9.2 & 7.9 & 6.6 & 6.1 \\
\hline Male gender & 50.7 & 50.3 & 51.5 & 50.9 & 52.8 & 52.8 \\
\hline Special health care needs ${ }^{\star \star \star}$ & 3.6 & 3.3 & 3.9 & 4.9 & 4.5 & 3.6 \\
\hline Number of well-child visits $<3$ years ${ }^{\star \star \star}$ & $3.5(2.0)$ & $3.1(2.0)$ & $4.0(1.7)$ & $4.8(1.4)$ & $5.2(1.2)$ & $5.7(1.2)$ \\
\hline Received caries-related treatment before age $3^{*}$ & 4.6 & 4.6 & 4.1 & 5.7 & 4.7 & 6.3 \\
\hline Received dental services in health department ${ }^{\star \star \star}$ & 18 & 12.7 & 32.1 & 29.6 & 26.5 & 27.4 \\
\hline \multicolumn{7}{|l|}{ County-level variables } \\
\hline Medicaid eligibles $<18$ years per 10000 population ${ }^{\star \star \star}$ & $469.1(141.0)$ & $459.4(140.8)$ & $476.7(132.7)$ & $497.2(139.8)$ & $515.8(145.7)$ & $531.7(150.5)$ \\
\hline Primary care medical providers per 10000 population ${ }^{\star \star \star}$ & $4.2(2.0)$ & $4.3(2.0)$ & $4.3(2.0)$ & $4.1(1.7)$ & $4.0(1.6)$ & $3.8(1.3)$ \\
\hline Dentists per 10000 population ${ }^{\star \star \star}$ & $3.8(1.8)$ & $3.9(1.8)$ & $3.6(1.6)$ & $3.4(1.4)$ & $3.3(1.4)$ & $3.1(1.4)$ \\
\hline \multicolumn{7}{|l|}{ Percentage of county with fluoridated water ${ }^{\star \star}$} \\
\hline $0 \%-24 \%$ of county population & 6.5 & 6.8 & 6.7 & 5.6 & 4.6 & 4.1 \\
\hline $25 \%-49 \%$ of county population & 3.5 & 3.3 & 3.2 & 3.7 & 5.1 & 9.7 \\
\hline $50 \%-74 \%$ of county population & 11.3 & 12.3 & 9 & 8.1 & 9.1 & 11.2 \\
\hline$\geq 75 \%$ of county population & 84.6 & 83.9 & 86.5 & 87.6 & 85.9 & 81.6 \\
\hline
\end{tabular}

Data are presented as means (SDs) or percentages. Although not included in the table, we also examined the rurality of the county. $P$ values were calculated by Kruskal-Wallis rank tests for ordinal variables, analysis of variance for continuous variables, and $\chi^{2}$ tests for binary and categorical variables. ${ }^{*} P<.05$, ${ }^{\star \star} P<.01,{ }^{\star \star \star} P<.001$.

Overall, $47.9 \%$ of children had $>0$ $\mathrm{dmft}$ and $25.3 \%$ had $>0 \mathrm{dt}$ by the time they entered kindergarten. Children had an average of $2.19 \mathrm{dmft}$ (SD = 3.19) and $0.76 \mathrm{dt}(\mathrm{SD}=1.78)$. Results of the Kruskal-Wallis test indicated that dmft, but not dt, differed significantly between children with 0 , $1,2,3$, and $\geq 4$ visits with POHS. The unadjusted mean number of $\mathrm{dmft}$ and $\mathrm{dt}$ was lowest among children who received $\geq 4$ POHS visits $(\mathrm{dmft}=1.76$, $\mathrm{SD}=2.98 ; \mathrm{dt}=0.51, \mathrm{SD}=1.34)$ and highest among children with 0 POHS visits $(\mathrm{dmft}=2.23, \mathrm{SD}=3.22 ; \mathrm{dt}=$ $0.78 ; \mathrm{SD}=1.82$ ).

\section{Adjusted Analysis}

Children with $\geq 4$ visits with POHS were predicted to have 0.39 fewer dmft, on average, than those with 0 visits (Table 2). As shown in Fig 1, the adjusted marginal mean number of $\mathrm{dmft}$ was predicted to be lower at a statistically significant level among children with $\geq 4$ visits with POHS (1.82; 95\% CI: 1.55 to 2.09) than 0 (2.21; $95 \%$ CI: 2.16 to 2.25$)$ or 2
(2.03; 95\% CI: 1.90 to 2.16 ) visits, and nearly significantly lower than 1 visit (2.20; $95 \%$ CI: 2.08 to 2.32 ). This outcome reflects results from the second part of the ZINB model in which children at risk of dmft with $\geq 4$ visits had significantly lower mean dmft than did children with 0 visits (incident rate ratio: $0.84 ; 95 \%$ CI: 0.76 to 0.94 ) (Table 2).

Table 2 presents the results of the ZINB model used to estimate the adjusted number of dt. Although children with 2 visits had significantly fewer predicted dt compared with 0 visits (Table 2), Fig 2 shows that the adjusted marginal mean number of $\mathrm{dt}$ was similar for all groups ( 0 visits $=0.77$ [95\% CI: 0.72 to 0.83 ]; 1 visit $=0.77$ [95\% CI: 0.70 to 0.85 ]; 2 visits $=0.68$ [ $95 \%$ CI: 0.61 to 0.75 ]; 3 visits $=0.79$ [95\% CI: 0.66 to 0.91$] ; \geq 4$ visits $=0.61$ [95\% CI: 0.46 to 0.76$]$ ].

\section{DISCUSSION}

Students enrolled in kindergarten who had $\geq 4$ medical visits with comprehensive POHS before their third birthday experienced fewer caries than those who did not receive these services. Previous studies of NC's POHS program have provided circumstantial evidence of improved oral health status on the basis of administrative claims, including a reduction in dental caries-related treatments and Medicaid payments up to 6 years of age. ${ }^{18,19}$ This study provides the first empirical evidence that comprehensive POHS provided by physicians in nondental primary care settings as part of a statewide Medicaid benefit reimbursement policy are associated with a reduction in dental caries in children.

The reduction in average adjusted dmft score per child was 0.39 ( 0 visits $=2.21, \geq 4$ visits $=1.82$ ), which is a $17.7 \%$ reduction. Although the difference between groups is statistically significant, it is difficult to assign clinical meaning at the individual level. This percentage reduction is within the range observed among randomized 


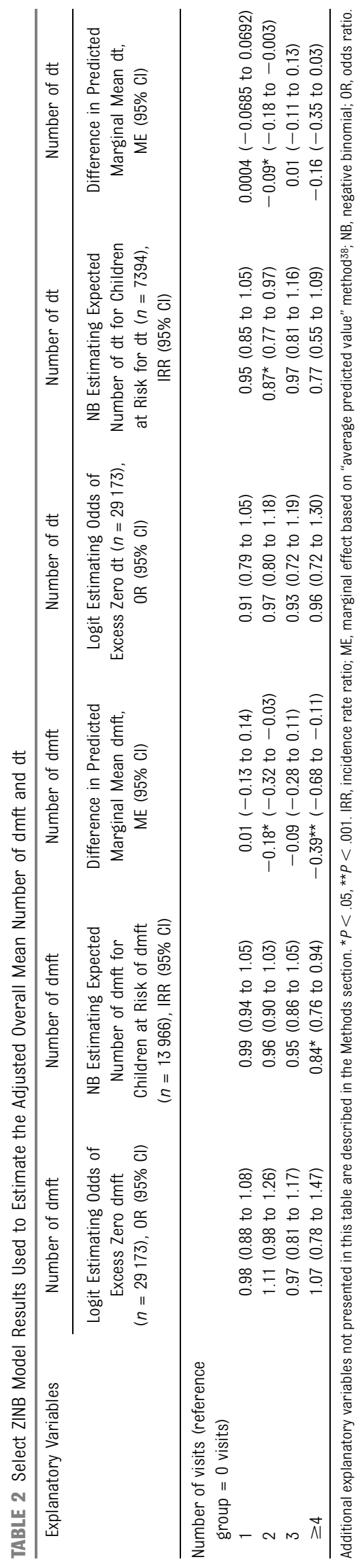

controlled trials included in systematic reviews examining the effectiveness of fluoride varnishes for preventing caries in primary teeth. 38,39 Our result is also similar to the $18 \%$ reduction in caries increment found in 1 of 3 randomized controlled trials cited by the USPSTF in support of its fluoride varnish "B" recommendation. ${ }^{39,40}$ At an individual level, we believe that the observed reduction in dental caries is an important finding. Treatment can be difficult and often requires costly hospitalizations with risk of adverse outcomes, including impaired cognitive development and death. ${ }^{41,42}$

The NC Medicaid program reimburses medical providers for a bundled set of POHS, including parental oral health counseling, screening, caries risk assessment, and fluoride varnish application. We are not able to separate the effects of each service on oral health outcomes examined in this study. No trials have evaluated the effectiveness of parental counseling alone on oral health outcomes. ${ }^{11,40}$ In its systematic review of dental caries prevention in children $<5$ years of age, the USPSTF identified 2 studies in medical offices that included parental education as part of a multifaceted intervention, both of which showed beneficial results. ${ }^{40}$

Among the different types of POHS provided, fluoride varnish has the strongest available evidence of a preventive effect for the primary dentition. ${ }^{39}$ Our biological understanding of the mechanisms by which fluoride prevents caries supports its effectiveness regardless of who applies it. The American Academy of Pediatrics and the USPSTF recommend that physicians apply fluoride varnish as soon as the first tooth erupts on the basis of inferences from studies in dental practitioners. ${ }^{11,40}$ Increasing the number of POHS visits per child is essential for promoting oral health because we observed a threshold effect of 4 visits. To prevent and control the development of caries until young children can more easily establish a dental home, NC Medicaid recommends delivery of POHS during already scheduled well-child visits at $6,9,12,15,18,24$, and 36 months. ${ }^{43}$ The content and periodicity of POHS vary by state and some Medicaid programs reimburse POHS up to older ages. ${ }^{12}$ Although most state Medicaid programs reimburse for fluoride varnish delivered in medical offices, ${ }^{12}$ the practice is not common nationally. 13

Medicaid-enrolled kindergarten students included in our sample were found to have a high prevalence of untreated caries. Approximately 1 in 4 students had caries that showed no evidence of treatment. Although children with $\geq 4$ POHS visits had experienced less disease overall than those with no visits, they had the same amount of $\mathrm{dt}$ in kindergarten. The high levels of $d t$ among students receiving POHS supports implementation of strategies to improve the quality of screening and referral services within medical practices.

Screening and referral are important components of oral health services in medical settings, but their effectiveness depends on the successful completion of a number of steps in a complex and often challenging process. A physician must do the following: (1) accurately identify risk and disease status of the child, which calls for the use of a risk assessment tool; (2) determine referral needs on the basis of this assessment; (3) advise the parent on a dental referral; and (4) provide services to support the referral, particularly for low-literacy caregivers who can experience difficulty in navigating the dental care system for their child.

Unfortunately, little evidence is available about best practices and barriers at each step in the screening 


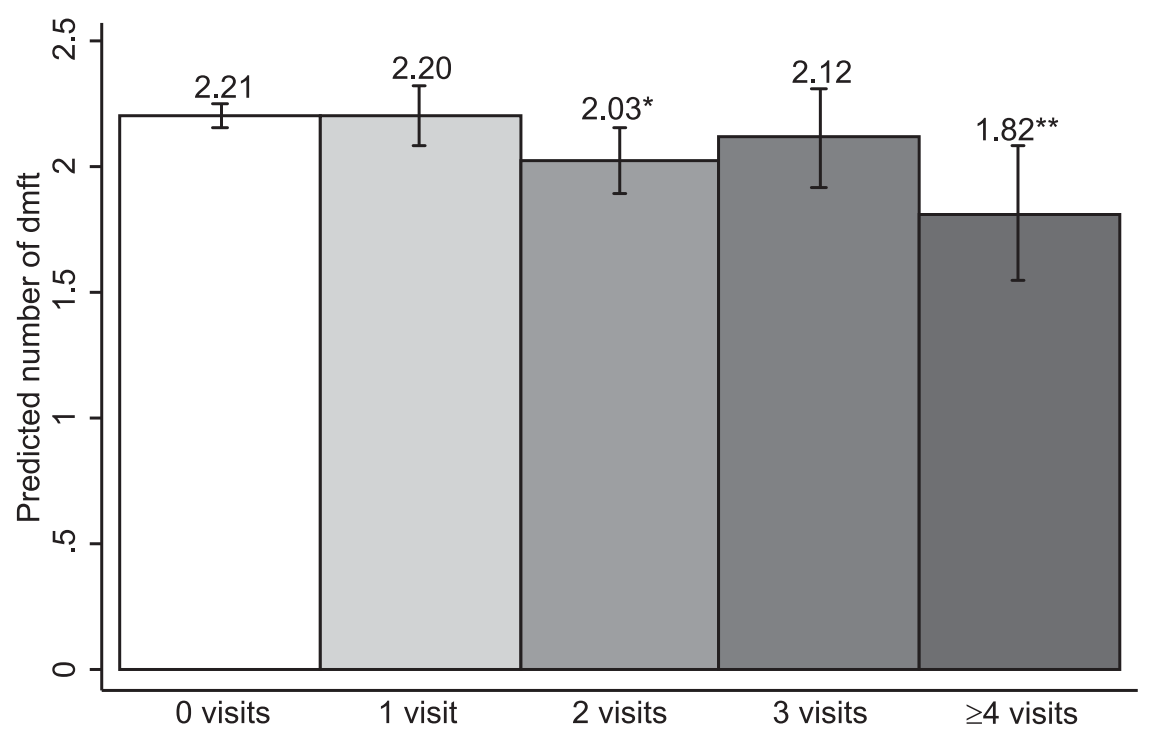

FIGURE 1

Predicted mean number of dfmt according to number of visits. Wald tests were used to examine differences in predicted dmft compared with 0 visits: ${ }^{\star} P<.05,{ }^{\star \star} P<.001$. Error bars represent $95 \%$ confidence intervals. and referral process. ${ }^{11,40}$

Pediatricians can identify children with cavitated lesions with an acceptable level of accuracy, but they are less accurate in identifying and assessing individual risk factors ${ }^{13,14,44,45}$ and tend to underrefer.46,47 Nationally, approximately half of pediatricians screen most patients for caries. ${ }^{13}$ Although physicians are more likely to refer infants and toddlers with obvious disease, dentists prefer that they refer before disease is present. ${ }^{48}$ Finally and importantly, evidence supports the conclusion that primary care referrals increase the use of dental homes, but that they are only partially effective in achieving continuity of care between medical and dental settings. ${ }^{49}$

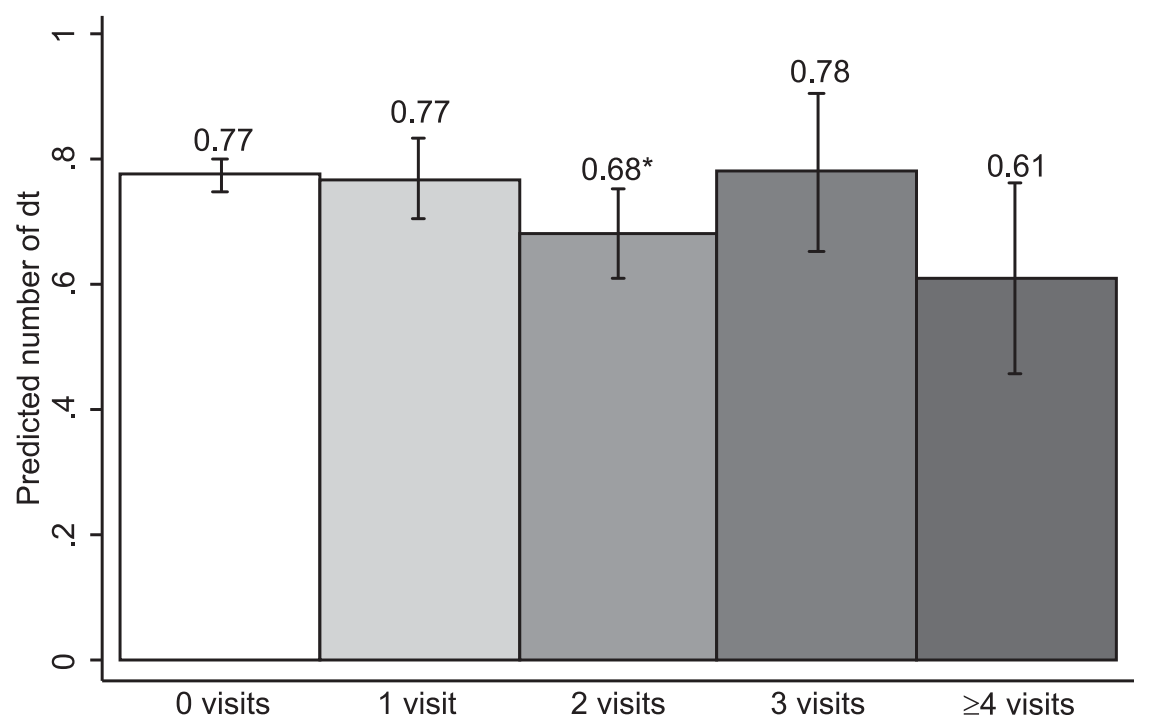

FIGURE 2

Predicted mean number of $\mathrm{dt}$ according to number of visits. Wald tests were used to examine differences in predicted dt compared with 0 visits: ${ }^{\star} P<.05$, ${ }^{\star \star} P<.001$. Error bars represent $95 \%$ confidence intervals.
Our assessment of the literature and results of this study lead us to conclude that multifaceted interventions targeted to the referral process along with rigorous evaluation of these efforts are needed to help ensure an effective outcome. Recently, this problem has received increased focus at the state and national levels. ${ }^{50-52}$ A long list of potential interventions has been proposed, including the following: training physicians and dentists to use risk-based referral guidelines, development and monitoring of performance measures, incorporation of oral health risk status indicators in electronic health records, and online training approved for continuing medical education. The lack of information on the feasibility and effectiveness of these proposed strategies provides the basis for an extensive research agenda for screening and referral by physicians.

The individual risk profile of children who did and did not receive POHS is unknown, and these differences may bias outcomes. We adjusted for potential confounders, but unobserved differences could still bias the results. Some evidence from other studies suggests that POHS are more likely to be received by children at high risk of caries, because POHS visits are more likely to be made by nonwhites, by Hispanics, in counties with fewer dentists, and in more rural counties, all risk factors for dental caries. ${ }^{17}$ In 1 study, the strongest predictor of follow-up visits was among those who reported that their child went to bed with a bottle or sippy cup. ${ }^{53}$

\section{CONCLUSIONS}

Physician-based POHS can help improve the oral health of children. Medical visits with POHS were associated with a reduction in overall mean dmft in children. We found no difference in the overall mean number of $\mathrm{dt}$ between those with and 
without POHS, suggesting that families continue to face barriers to obtaining dental treatment of young children. On the basis of evidence of effectiveness observed in this study, enhanced efforts should be taken to expand the delivery of comprehensive POHS in medical settings, particularly in those communities where access to dentists remains limited.

Furthermore, development and testing of strategies to improve the linkage between medical and dental offices are needed to ensure the continuity of care for those children receiving POHS in medical settings.

\section{ABBREVIATIONS}

CI: confidence interval

dmft: decayed, missing, and filled teeth

$\mathrm{dt}$ : untreated decayed teeth

IPTW: inverse probability of treatment weight

NC: North Carolina

POHS: preventive oral health services

USPSTF: US Preventive Services Task Force

ZINB: zero-inflated negative binomial

\section{REFERENCES}

1. White BA, Caplan DJ, Weintraub JA. A quarter century of changes in oral health in the United States. J Dent Educ. 1995;59(1):19-57

2. US Department of Health and Human Services and the National Institute of Dental and Craniofacial Research. Oral Health in America: A Report of the Surgeon General. Rockville, MD: US Department of Health and Human Services, National Institute of Dental and Craniofacial Research, National Institutes of Health; 2000

3. Centers for Disease Control and Prevention. Data applications: oral health data. Available at: http://drc.hhs. gov/dqs.htm. Accessed September 9, 2013

4. Dye BA, Li X, Thornton-Evans G. Oral health disparities as determined by selected Healthy People 2020 oral health objectives for the United States, 2009-2010. NCHS Data Brief 2012:104:1-7

5. Snyder A. Increasing access to dental care in Medicaid: targeted programs for four populations. March 2009. Available at: www chcf.org/ /media/MEDIA\%20LIBRARY\% 20Files/PDF/I/PDF\%20IncreasingAccessToDentalCarelnMedicaid.pdf. Accessed May 15, 2012

6. Institute of Medicine. Advancing Oral Health in America. Washington, DC: The National Academies Press; 2011

7. Carver L, Cheung K, Revels M, et al. Workforce innovations in oral health: innovations that address socioeconomic, cultural, and geographic barriers to preventive oral health care. Robert Wood Johnson Foundation. Published September 2013. Available at: www.rwjf. org/content/dam/farm/reports/reports/ 2013/rwjf407853. Accessed January 9, 2014

8. Association of State and Territorial Dental Directors. Best practice approach: prevention and control of early childhood tooth decay. Updated February 2013. Available at: www.astdd. org/docs/BPAEarlyChildhood.pdf. Accessed January 9, 2014

9. National Academy for State Health Policy. Engaging primary care medical providers in children's oral health. Published September 2009. Available at: http://nashp.org/sites/ default/files/EngagingPrimaryCareMedicalProvidersCOH.pdf?q=files/EngagingPrimaryCareMedicalProvidersCOH.pdf. Accessed May 15, 2012

10. American Academy of Pediatrics, Section on Oral Health. Maintaining and Improving the Oral Health of Young Children. Pediatrics. 2014;134:1224-1229

11. Moyer VA; US Preventive Services Task Force. Prevention of dental caries in children from birth through age 5 years: US Preventive Services Task Force recommendation statement. Pediatrics. 2014;133(6):1102-1111

12. Sams LD, Rozier RG, Wilder RS, Quinonez RB. Adoption and implementation of policies to support preventive dentistry initiatives for physicians: a national survey of Medicaid programs. Am J Public Health. 2013;103(8):e83-e90

13. Quinonez RB, Kranz AM, Lewis CW, et al. Oral health opinions and practices of pediatricians: updated results from a national survey. Acad Pediatr. 2014; 14(6):616-623

14. Pierce KM, Rozier RG, Vann WF Jr. Accuracy of pediatric primary care providers' screening and referral for early childhood caries. Pediatrics. 2002; 109(5). Available at: www.pediatrics.org/ cgi/content/full/109/5/E82

15. Kressin NR, Nunn ME, Singh $H$, et al Pediatric clinicians can help reduce rates of early childhood caries: effects of a practice based intervention. Med Care. 2009;47(11):1121-1128

16. Okunseri C, Szabo A, Jackson S, Pajewski NM, Garcia RI. Increased children's access to fluoride varnish treatment by involving medical care providers: effect of a Medicaid policy change. Health Serv Res. 2009;44(4):1144-1156

17. Rozier RG, Stearns SC, Pahel BT, Quinonez RB, Park J. How a North Carolina program boosted preventive oral health services for low-income children. Health Aff (Millwood). 2010;29(12):2278-2285

18. Pahel BT, Rozier RG, Stearns SC, Quiñonez RB. Effectiveness of preventive dental treatments by physicians for young Medicaid enrollees. Pediatrics. 2011; 127 (3). Available at: www.pediatrics.org/ cgi/content/full/127/3/e682

19. Stearns SC, Rozier RG, Kranz AM, Pahel BT, Quiñonez RB. Cost-effectiveness of preventive oral health care in medical offices for young Medicaid enrollees. Arch Pediatr Adolesc Med. 2012;166(10): 945-951

20. Hendrix KS, Downs SM, Brophy G, Carney Doebbeling C, Swigonski NL. Threshold analysis of reimbursing physicians for the application of fluoride varnish in young children. J Public Health Dent 2013;73(4):297-303

21. Rozier RG, Sutton BK, Bawden JW, Haupt K, Slade GD, King RS. Prevention of early childhood caries in North Carolina medical practices: implications for research and practice. J Dent Educ. 2003; 67(8):876-885

22. King RS, Satterfield WC, Rozier RG. A statewide system for dental caries in kindergarten children [abstract 946] J Dent Res. 1998;77(A):224

23. King RS, Rozier RG. School-based dental disease prevention and oral health education: programs of the North 
Carolina oral health section. N C Med J. 2008;69(6):490-494

24. North Carolina Department of Health and Human Services, Division of Medical Assistance. Medicaid in North Carolina: annual report state fiscal year 2007. Raleigh, NC. Published December 2008. Available at: www.ncdhhs.gov/dma/ 2007report/2007report.pdf. Accessed July 30, 2013

25. Beil H, Preisser JS, Rozier RG. Accuracy of record linkage software in merging dental administrative data sets. J Public Health Dent. 2013;73(2):89-93

26. Beil H, Rozier RG, Preisser JS, Stearns SC, Lee JY. Effect of early dental office visits on dental caries experience. Am J Public Health. 2014;104(10):1979-1985

27. American Academy of Pediatrics. Medicaid facts: North Carolina. Published September 2012. Available at: www.aap.org/en-us/advocacy-and-policy/ federal-advocacy/access-to-care/ Medicaid\%20Fact\%20Sheets/ NorthCarolina.pdf. Accessed April 9, 2014

28. Andersen RM. Revisiting the behavioral model and access to medical care: does it matter? J Health Soc Behav. 1995;36(1): $1-10$

29. Powell LV. Caries prediction: a review of the literature. Community Dent Oral Epidemiol. 1998;26(6):361-371

30. Economic Research Service. Rural-urban continuum codes. Washington, DC: US Department of Agriculture. Updated 2012. Available at: www.ers.usda.gov/ Data/RuralUrbanContinuumCodes/. Accessed June 1, 2012

31. Cecil G. Sheps Center for Health Services Research. North Carolina health professionals data system. Available at: www.shepscenter.unc.edu/hp/profiles. htm. Accessed May 20, 2012

32. North Carolina Division of Medical Assistance. Authorized Medicaid and health choice for children eligibles reports. North Carolina Department of Health and Human Services. Updated 2012. Available at: www.ncdhhs.gov/dma/ elig/index.htm. Accessed May 20, 2012

33. Rosenbaum PR, Rubin DB. The central role of the propensity score in observational studies for causal effects. Biometrika. 1983;70:41-55
34. Hirano K, Imbens GW. Estimation of causal effects using propensity score weighting: an application to data on right heart catheterization. Health Serv Outcomes Res Methodol. 2001;2:259-278

35. Austin PC. A critical appraisal of propensity-score matching in the medical literature between 1996 and 2003. Stat Med. 2008;27(12):2037-2049

36. Preisser JS, Stamm JW, Long DL, Kincade ME. Review and recommendations for zero-inflated count regression modeling of dental caries indices in epidemiological studies. Caries Res. 2012;46(4):413-423

37. Albert JM, Wang W, Nelson S. Estimating overall exposure effects for zero-inflated regression models with application to dental caries. Stat Methods Med Res. 2014;23 (3) :257-278

38. Carvalho DM, Salazar M, Oliveira BH, Coutinho ESF. Fluoride varnishes and caries incidence decrease in preschool children: a systematic review. Rev Bras Epidemiol. 2010;13:1-11

39. Marinho VC, Worthington HV, Walsh T, Clarkson JE. Fluoride varnishes for preventing dental caries in children and adolescents. Cochrane Database Syst Rev. 2013;7:CD002279

40. Chou R, Cantor A, Zakher B, Mitchell JP, Pappas M. Preventing dental caries in children $<5$ years: systematic review updating USPSTF recommendation. Pediatrics. 2013;132(2):332-350

41. Jevtovic-Todorovic V. Anesthesia and the developing brain: are we getting closer to understanding the truth? Curr Opin Anaesthesiol. 2011;24(4):395-399

42. Lee HH, Milgrom P, Starks H, Burke W. Trends in death associated with pediatric dental sedation and general anesthesia. Paediatr Anaesth. 2013;23(8): $741-746$

43. Bright Futures; American Academy of Pediatrics. Recommendations for preventive pediatric health care. Updated 2008. Available at: www.aap.org/ en-us/professional-resources/practicesupport/Periodicity/Periodicity\% 20Schedule_FINAL.pdf. Accessed December 23, 2014

44. Dumas SA, Weaver KE, Park SY, Polk DE, Weyant RJ, Bogen DL. Accuracy of visible plaque identification by pediatric clinicians during well-child care. Clin Pediatr (Phila). 2013;52(7):645-651

45. Herndon JB, Tomar SL, Lossius MN, Catalanotto FA. Preventive oral health care in early childhood: knowledge, confidence, and practices of pediatricians and family physicians in Florida. J Pediatr. 2010;157 (6):1018-1024, e2

46. dela Cruz GG, Rozier RG, Slade G. Dental screening and referral of young children by pediatric primary care providers. Pediatrics. 2004;114(5). Available at: www.pediatrics.org/cgi/content/full/114/ 5/e642

47. Long CM, Quinonez RB, Beil HA, et al. Pediatricians' assessments of caries risk and need for a dental evaluation in preschool aged children. BMC Pediatr. 2012;12:49-56

48. Long CM, Quinonez RB, Rozier RG, Kranz AM, Lee JY. Barriers to pediatricians' adherence to AAP oral health referral guidelines: North Carolina general dentists' opinions. Pediatr Dent. 2014;36(4):309-315

49. Beil HA, Rozier RG. Primary health care providers' advice for a dental checkup and dental use in children. Pediatrics. 2010;126(2). Available at: www.pediatrics. org/cgi/content/full/126/2/e435

50. North Carolina Institute of Medicine. The North Carolina oral health action plan for children enrolled in Medicaid and NC health choice. Morrisville, NC: North Carolina Institute of Medicine. Updated 2013. Available at: www.nciom.org/wpcontent/uploads/2013/07/ ChildPrev0ralHealthWeb_062813.pdf. Accessed January 29, 2014

51. American Academy of Pediatrics. EQIPP: oral health in primary care. Available at: http:// eqipp.aap.org/. Accessed January 30, 2104

52. Boulter S. Use of risk assessment tool in primary care. Presented at: National Oral Health Conference; Milwaukee, WI. Presented May 2, 2012. Available at: www.nationaloralhealthconference.com/ docs/presentations/2012/05-02/Suzanne \%20Boulter.pdf. Accessed January 29, 2014

53. Quiñonez RB, Pahel BT, Rozier RG, Stearns SC. Follow-up preventive dental visits for Medicaid-enrolled children in the medical office. J Public Health Dent. 2008;68(3):131-138 